\title{
Variaciones idealistas: Schopenhauer, la "cosa en si" y el problema de la negación
}

\section{Idealist Variations: Schopenhauer, the "Thing in Itself," and the Problem of Negation}

\section{Zaida Verónica Olvera Granados}

Universidad Autónoma del Estado de Morelos

\section{Resumen:}

A 200 años de la redacción de El mundo como voluntad y representación sigue siendo un desiderátum el hablar de Schopenhauer como miembro de la tradición filosófica alemana conocida como idealismo alemán. El propio filósofo se reclamó un heredero legítimo de la filosofía kantiana, la cual es, entre otras cosas, el gran pilar filosófico del idealismo alemán. Y no sólo se reclama su heredero, sino que, como los propios idealistas, también intentó reformular o neutralizar la problemática en torno a la "cosa en si”. En este trabajo se analizará la estrategia que Schopenhauer siguió para reformular dicha problemática. La estrategia en cuestión es una doble comprensión de la negación: la negación encarnada por aquello que Schopenhauer denomina fenómeno, y la negación de la voluntad. La caracterización de ambos tipos de negación permitirá tener una idea más clara del lugar que ocupa Schopenhauer en la discusión, propiamente postkantiana, acerca de la "cosa en sî" o lo incondicionado (das Unbedingt).

Palabras clave: cosa en sí, idealismo alemán, voluntad, lo incondicionado, Schopenhauer, Kant

\section{Abstract:}

Two hundred years after the appearance of The World as Will and Representation, talking about Schopenhauer as a member of the German philosophical tradition known as German idealism continues to be a desideratum. The philosopher himself claimed to be a legitimate heir of Kantian philosophy, which is, among other things, the great philosophical pillar of German idealism. Not only does he claim to be its 
heir but, as the very idealists did, he also tried to reformulate or neutralize the problem regarding the "thing-in-itself". This paper will analyze the strategy followed by Schopenhauer to reformulate said problematic. The strategy at issue is a double understanding of negation: negation embodied by that which Schopenhauer calls phenomenon, and the negation of will. The characterization of both types of negation will allow a clearer idea of Schopenhauer's place in the debate, specifically post-Kantian, on the "thing-in-itself" or the unconditioned (das Unbedingt).

Keywords: thing in itself, German idealism, will, the unconditioned, Schopenhauer, Kant

A 200 años de la redacción de El mundo como voluntad y representación sigue siendo una tentación hablar de Schopenhauer como miembro de la tradición filosófica alemana conocida como idealismo alemán (Hühn, 2005: 55-69). Es inusual tener en cuenta que dicho libro salió a la luz dos años después de la publicación del último volumen de la Ciencia de la lógica de Hegel y nueve años después del Tratado sobre la esencia de la libertad humana de Schelling, que Schopenhauer reconoció haber leído y con el cual se han establecido ya algunas relaciones de parentesco (Hühn, 2005).

Sin duda, el hecho de ser contemporáneo de una corriente filosófica no nos vuelve inmediatamente sus miembros, como tampoco basta el haber leído un texto para que se nos afilie al autor. Pero en el caso de Schopenhauer, lo dicho hasta aquí hace más que situarlo en el contexto filosófico de la época: a lo anterior se suma el hecho de que el propio Schopenhauer se reclama heredero de la filosofía kantiana, la cual es, entre otras cosas, el gran pilar filosófico del idealismo alemán. Y no sólo se reclama su heredero, sino que, como los propios idealistas, Schopenhauer también intentó reformular o neutralizar la problemática que dio nacimiento al movimiento filosófico en contra del cual Schopenhauer intentó siempre posicionarse (quizá sin lograrlo del todo), me refiero a la problemática de la "cosa en sí. Hay que tener en cuenta, además, que Schopenhauer, como los idealistas de la primera hora, consideró necesaria una reinterpretación del carácter negativo, o limitativo, atribuido por Kant a dicho concepto. ${ }^{1}$ Es a partir de este último punto que el presente trabajo se estructura.

${ }^{1}$ Claro que el problema de la negación no es propio de una corriente filosófica. Lo que caracteriza al problema de la negación como patrimonio del idealismo alemán es el punto de partida de dicha problemática. Éste puede situarse en la negatividad del concepto kantiano de "cosa en sî". Kant carac- 
Para comenzar, debo señalar que el establecer puntos de encuentro entre Schopenhauer y el idealismo no me ha impedido tener en cuenta que, a su vez, existe entre ellos una diferencia fundamental, a saber, un profundo pesimismo epistemológico que se encuentra en las antípodas del valor que el idealismo le atribuye a la razón. ${ }^{2}$ En relación al problema que me interesa, la negación, esta diferencia juega un papel decisivo: mientras que en el caso de Hegel, por ejemplo, las limitaciones a las que se enfrenta la razón en su trayecto de autoconocimiento y autoconstitución son simultáneamente superadas y retenidas por ella misma, para Schopenhauer la "cosa en sí" no es un mero momento negativo producido bajo una figura de la conciencia. Más aun (y esto es lo más importante) Schopenhauer considera que la desaparición (y no superación) del límite que separa al fenómeno de la cosa en sí no es una operación racional.

La puesta en cuestión del carácter inaccesible de la radical negatividad (nibil negativum) de la "cosa en sí" se escinde en dos formas de negación: la negación encarnada por aquello que Schopenhauer denomina fenómeno y la negación de la voluntad. ${ }^{3}$ La caracterización de ambos tipos de negación permitirá tener una idea más clara del lugar que ocupa Schopenhauer en la discusión, propiamente postkantiana, acerca de la "cosa en sî" o lo incondicionado (das Unbedingt).

En primer lugar, abordaré brevemente la transformación que el concepto de "cosa en sî" sufre en la obra de Schopenhauer, pero no para detenerme en las implicaciones generales de dicho cambio, sino únicamente para comprender cómo es que, por oposición lógica, se determina al fenómeno con un régimen de negatividad ausente en el primer concepto. En segundo lugar, indagaré sobre las consecuencias que el concepto de destino tiene sobre la negatividad determinada del fenómeno. Por último, me referiré a la negación de la voluntad en relación al concepto de Gracia (Gnade). Será a través de este concepto que se explique el ca-

terizó a la cosa en sí como un concepto negativo que determina los límites del conocimiento humano Ver Immanuel Kant, Critica de la razón pura ( $K r V$ ), B XIX-XX. Pero ¿̨cómo se justifica, si es que eso es posible, el recurso a un concepto tal en un texto sobre la validez objetiva de nuestro conocimiento del mundo? Recordemos aquella frase en donde Jacobi formula la encrucijada en la que la cosa en sí kantiana lo situaba y situaba a toda su generación: "no puedo entrar en el sistema, sin admitir este presupuesto de la "cosa en si" y no puedo permanecer en él admitiéndolo" (citado en Ochoa, 2003: 416).

${ }^{2}$ No se piense, sin embargo, que el papel preponderante que Hegel le atribuye a la razón es un reflejo de un (inexistente) optimismo hegeliano o confianza en los poderes del intelecto humano. Cuando Hegel habla de la razón se refiere a la actividad de la realidad efectiva racional.

${ }^{3}$ El problema de la negatividad o de la nada implica también el problema del nihilismo. Sin embargo, dado que ese concepto tiene resonancias culturales mucho más amplias, no me es posible tratarlo aquí. Remito para ello a Dastur (2018: 149-176). 
rácter irracional de la desaparición del límite que se impone con el concepto de "cosa en sî”, o, como la llama Schopenhauer, la voluntad.

\section{La negatividad del fenómeno y la positividad de la voluntad}

Echemos una muy breve mirada al problema al que el joven de 26 años está apuntando con la redacción de El mundo como voluntad y representación: Fichte, a cuyos cursos había asistido Schopenhauer, ${ }^{4}$ había esgrimido una severa crítica al "dogmatismo" kantiano, dogmatismo perpetuado por la admisión injustificada de algo más elevado que el Yo absoluto (Fichte, 1965: 279). Para Fichte el Yo absoluto debía sustituir a la "cosa en si” y debía unificar los temas centrales de la filosofía teórica y de la filosofía práctica kantiana. Para referir dicha convergencia Fichte denominó a la "cosa en sî" la Tathandlung. De esta manera la "cosa en sí" aparecía como aquello que no podía volverse objeto de conocimiento para la conciencia, sino que debía ser fundamento sin condiciones de todo lo condicionado. Mediante la caracterización de la Tathandlung como pura espontaneidad, o puro acto de ser y conocerse, Fichte creía escapar de la circularidad del conocimiento objetivo. Ello, como se sabe, abrió de par en par las puertas hacia la idea del autoconocimiento divino; y dicha puerta fue audazmente franqueada por el joven Schelling, para quien en "Del Yo como principio de toda la filosofía", la "cosa en sí" adquirió proporciones exorbitantes, transformándose en una sustancia, similar a la spinocista, al poseer intuición intelectual (Schelling, 1907).

Las caracterizaciones de la "cosa en sí" en el idealismo alemán son positivas, al menos en estas primeras versiones. Pero para Schopenhauer, quien mira con ojos orientales la filosofía alemana, y con ojos alemanes el pensamiento oriental, las respuestas ofrecidas hasta entonces al problema de la "cosa en sî" no le parecen plausibles. Ninguna de las dos opciones - la doctrina del Yo de Fichte y la filosofía de la identidad de Schelling (Schopenhauer, 1986: $\$ 7,60-61)^{5}$ — ofrecen una respuesta satisfactoria a la pregunta por la esencia del mundo ya que ambas asumen

\footnotetext{
${ }^{4}$ Tal y como afirma Safranski, Schopenhauer acogió la filosofía de Fichte primero con entuasiasmo para luego rechazarla. Esto último se percibe en el propio texto de Schopenhauer El mundo como voluntad y representación (Safranski, 1991: 199; Schopenhauer, 1986: \$7, 66-67).

${ }^{5}$ Es en estas páginas en donde Schopenhauer se desmarca de la filosofía de la identidad. Ésta no es únicamente aburrida palabrería [langweilige Windbeuteleien], lo cual es ya una objeción a ojos del gran estilista Schopenhauer, sino que, además, esta doctrina permanece, a su pesar, en el pensamiento de la causalidad- o el yo causa al no yo, o viceversa, y por eso es mera variación sobre el tema del principio de razón suficiente.
} 
el principio de razón suficiente, con lo cual permanecen en el mundo de la representación y no alcanzan la verdadera naturaleza de lo que está en cuestión (Schopenhauer, 1986). ${ }^{6}$

El texto de Schopenhauer ofrece otro tipo de respuesta a la pregunta sobre qué es el mundo. Creyendo seguir a Kant, el joven autor afirma que el mundo es la "cosa en sí", aunque ésta sólo pueda ser referida como lo otro del fenómeno (Erscheinung). Ello significa, como afirman los Vedas, que tenemos frente a los ojos un velo, el velo de Maya, que nos impide ver las cosas como realmente son (Schopenhauer, 1986: \$3,37). A lo que se encuentra detrás de este velo Schopenhauer no lo llamará más "cosa en sî”, sino Voluntad. Por eso se pregunta: “¿Cuál es aquel otro lado de la representación, distinto toto genere de ella? ¿Qué es la Cosa en sí? — La voluntad: esa ha sido nuestra respuesta [...]" (Schopenhauer, 1986: \$24, 183). ${ }^{7}$

La voluntad, como la "cosa en sî", se encuentra fuera de las determinaciones subjetivas de la cognición, a saber, fuera del espacio y del tiempo y de la causalidad, por ello no puede ser aprehendida mediante el principio de razón suficiente. La Voluntad es aquello indeterminado, lo que carece de condición, es decir, de causalidad, y por tanto carece de razón de ser, es Grundlos (Schopenhauer, 1986: 173174). ${ }^{8}$ Sin embargo, a pesar de carecer de fundamento, ella constituye, de alguna manera, la esencia de los fenómenos (1986).

Siguiendo a Aristóteles, Schopenhauer afirma en la Cuádruple raíz del principio de razón suficiente que la esencia y la existencia son dos dimensiones que deben separarse. ${ }^{9}$ La precaución aristotélica que evita que se le atribuya existencia a la esencia es también una precaución que Schopenhauer adopta, de manera que mientras que el mundo como representación está regido por el principio de individuación o singularización de lo existente, no hay en el ámbito de la voluntad diferenciación ni, por

\footnotetext{
${ }^{6}$ Recordemos que para Schopenhauer la pregunta filosófica por excelencia no es para qué o de dónde, sino “¿qué es el mundo?" (Schopenhauer, 1986: \$15, 135).

${ }^{7}$ Respecto a la traducción, véase Schopenhauer (2009: 172). Traducción modificada.

${ }^{8}$ Contrariamente a lo que Schopenhauer considera que Fichte piensa, Schopenhauer no hace de lo indeterminado algo dependiente de procesos de la reflexión.

${ }^{9}$ Aristóteles, Analiticos Segundos, II, 7. Tomado de Schopenhauer, 1981: \$7, 38. Precisamente en este apartado Schopenhauer se regodea en una crítica mordaz tanto a Schelling — su escrito de 1809— como a Hegel, ya que considera que ninguno de los dos ha entendido la refutación al argumento ontológico ofrecida por Kant, en cuya base se encuentra la misma precisión airstotélica: el ser no es equivalente a existir. Sin embargo, al rechazar el "monismo" hegeliano, en Schopenhauer prevalece una especie de dualismo o, como se verá más adelante, emanantismo, que es también difícil de separar de posturas metafísicas.
} 
tanto, otredad. Así, frente a la negatividad de la representación del mundo de lo existente aparece la positividad de la voluntad, que es puro ser.

Sin embargo, la positividad de la voluntad no tiene en el mundo fenoménico su contraparte eleata. Es decir, la negatividad propia del mundo como fenómeno no es un absoluto no ser. Para Schopenhauer, quien sigue nuevamente a Aristóteles, el principio de individuación introduce otro tipo de negatividad, diferenciada de la absoluta negatividad, a saber, una negatividad determinada. Esto no significa otra cosa que ser en la medida en que un individuo no es lo que otro individuo es, o es, en la media en que no es su otro. Para explicarlo en términos spinocistas también podemos recurrir a la expresión Omnis determinatio est negatio.

La diferenciación entre la positividad de la voluntad y la negatividad determinada de las representaciones es entendida también por Schopenhauer como la diferencia entre la libertad y la necesidad. ${ }^{10}$ Con ello se refiere simplemente al hecho de que la libertad es carencia de determinación, contrapuesta a la determinación característica de la negatividad de los fenómenos. Estos últimos se encuentran necesariamente entrelazados. Por eso afirma:

En tanto que fenómeno, en tanto que objeto, cada cosa es absolutamente necesaria: esta misma cosa es, en si Voluntad, y en tanto que tal es completamente libre, por toda eternidad. El fenómeno, el objeto, se encuentra necesaria e invariablemente determinado dentro del encadenamiento de razones y consecuencias, [misma] que no puede tener ninguna interrupción. Sin embargo, la existencia en general de ese objeto y la manera en la que éste existe, es decir, la idea que se revela en él o, en otras palabras: su carácter, es inmediatamente fenómeno de la voluntad. Según la libertad de esta voluntad, ese carácter podría no existir en absoluto o ser originaria y esencialmente distinto; pero entonces toda la cadena de la que es miembro y que es ella misma fenómeno de la misma voluntad, sería también totalmente distinta: pero puesto que existe y se encuentra dentro de la serie de las razones y consecuencias, se encuentra siempre necesariamente determinada dentro de ella y por tanto no puede ni volverse otra, es decir, cambiar, ni salir de la serie, esto es, desaparecer. (Schopenhauer, 1986: \$55, 396; Schopenhauer, 2009: 344)

${ }^{10}$ Schopenhauer se refiere a la libertad como concepto negativo, pero ello solamente en la medida en que constituye la negación de la necesidad. Es el mismo procedimiento de oposición que se aplica a la caracterización de la "cosa en sî" como un concepto que mienta lo que no es el fenómeno. La negatividad y la positividad se determinan según el punto desde el cual se juzgue lo contrario (Schopenhauer, 1986: $\$ 55,395)$. 
Con esta cita se percibe que hay, en efecto, un tipo de negatividad que Schopenhauer asocia al hecho de que en el mundo fenoménico todo está determinado causalmente y todo tiene su razón de ser en otro. Este nivel de negación es, como se decía, el de la negación determinada. Ésta define a todas las cosas en el mundo fenoménico, incluidos los seres vivos, como los seres humanos. Desde el punto de vista de la voluntad, nosotros, en tanto que fenómenos, nos encontramos determinados por todos los eventos inscritos en la cadena causal de nuestra existencia.

El fenómeno que logre acceder a lo que se encuentra detrás del velo de Maya deberá, para tal efecto, liberarse de su principio de individuación. Sin embargo, puesto que dicho principio es lo que hace de aquel fenómeno un fenómeno individualizado, el acceso al mundo de la voluntad exige la anulación de sí mismo, es decir, la anulación o negación del fenómeno. Por tanto, es posible afirmar que el acceso a lo que se encuentra detrás del velo de Maya implica la negación de la negación determinada, la supresión de nuestra manera de existir fenoménica.

Pero como ya he indicado, si bien Schopenhauer comparte con los miembros del idealismo alemán la idea según la cual la "cosa en si”" no es un límite infranqueable, nuestro autor no considera que el acceso a ésta implique alguna actividad intelectual. No es la razón la encargada de desenmascarar los límites que se nos imponen, sino un elemento irracional que no depende tampoco de la voluntad individual. Ese elemento irracional es la gracia (die Gnade).

Este concepto representa la gran diferencia entre Schopenhauer y los idealistas mencionados hasta ahora. Ni el intelecto, pero tampoco la voluntad individual jugarán un papel en la explicación de cómo ocurre aquel tránsito hacia el mundo como voluntad. Veamos cómo es que Schopenhauer explica la posibilidad de lo que he llamado esta negación de la negación.

\section{De la negación determinada a la negación de la negación o negación de la voluntad. Ni voluntad ni intelecto}

Además de explicar el concepto de necesidad mediante la imagen de la cadena causal a la que todo fenómeno está sometido, Schopenhauer también se refiere a la relación entre la necesidad y el destino. ${ }^{11}$ El vínculo entre ambos conceptos se establece gracias a la introducción del concepto de Idea. Una comprensión más concreta del papel de las Ideas en Schopenhauer favorece la comprensión de su postura en

${ }^{11}$ Tal y como se observa en la última cita del apartado anterior. 
relación al problema de la negatividad pues con las ideas tenemos el sistema completo de escalonamiento ontológico en la cosmovisión schopenhaueriana.

Las ideas son producidas por la voluntad y son, a su vez, las fuentes originarias de la multiplicidad de los fenómenos. Las ideas se expresan en ellos (Schopenhauer, 1986: \$28, 254) haciendo que, a través de éstas, la voluntad también se manifieste en el mundo de la pluralidad y del cambio. A propósito de ello Vincent Stanek (2010) observa que hay en la teoría de las ideas un intento por parte de Schopenhauer de hacer la voluntad inmanente al mundo, como en la tradición neoplatónica. ${ }^{12}$ Este sesgo neoplatónico hace de la distinción entre esencia y existencia operada por Schopenhauer desde la Cuádruple raiz del principio de razón suficiente, una diferenciación menos aristotélica de lo que Schopenhauer quisiera admitir.

$\mathrm{Al}$ igual que los neoplatónicos, Schopenhauer le da movimiento al chorismos platónico ${ }^{13}$ y por ello entre la voluntad, que es la esencia del mundo, y el mundo existente, hay un mundo intermedio, comunicante, que es el de las ideas. Este terreno intermedio de las ideas es la clave para evitar una contradicción dentro del sistema de Schopenhauer pues hace innecesaria una explicación causal que clarifique la relación entre el mundo como voluntad y el mundo como representación.

Schopenhauer caracteriza las ideas como objetivaciones de la Voluntad y son ellas las que, a su vez, se objetivan para representarse en el mundo del fenómeno. Las ideas son esencias que son independientes las unas de las otras, carecen de existencia y por esa razón carecen de diferencia consigo mismas. En cuanto ideas no pueden considerarse ni como objetos particulares ni como pluralidades. Son, más

${ }^{12}$ A este escalonamiento que va de la voluntad a la representación, pasando por las ideas Schopenhauer lo designa como Abstufung y como se ha dicho, para Stanek esta explicación posee fuertes resonancias neoplatónicas. Véase Schopenhauer (1986) y Stanek (2010: 158).

${ }^{13}$ Según Erns Cassirer y Marc Boss, la categoría de emanación es el resultado de una mezcla ecléctica (y no de una síntesis armónica) entre la categoría platónica de trascendencia y la categoría aristotélica de movimiento. Las ideas en Schopenhauer parecen ser herencia del eclecticismo plotiniano. Véase la cita que Marc Boss hace de Ernst Cassirer en Boss (2010). Además, parece haber en Schopenhauer dos tipos de nada: una nada en cuanto carente de determinaciones, y otra determinada. Estas dos "nadas" explican el final del texto de Schopenhauer, al que referiremos en la próxima sección. Adelanto que las dos concepciones sobre la nada se leen ya en Plotino. Véase Juntunen (1996: 58): “[...] kein leeres Nicht, sondern in dem Sinne Nichts, dass es in absoluter Transzendenz über alles erhaben ist [...] Zweitens ist die Materie für Plotin Nichts [weil] sie von der wahrhaft seienden intelligiblen Welt geschieden ist. Sie sei nur ein schwaches Abbild des wahrhaft Seienden und als solches Nichts." Como Schopenhauer explica, mientras que el mundo como representación está regido por el principio de individuación o de determinación, la voluntad carece de ésta. Es, como para el primer idealismo, lo indeterminado, lo que carece de condición, es decir, de causalidad. Frente a la positiva "nada" de la voluntad, aparece la negatividad de la representación. 
bien, las formas eternas o prototipos de los objetos del mundo de la representación, pero no sometidas al principio de individuación (Schopenhauer, 1986: $\$ 25$ y \$30).

Ahora bien, según Schopenhauer, las ideas funcionan en los animales como género, sin embargo, en el caso de los seres humanos las ideas no se limitan a determinarnos genéricamente, sino que se singularizan al punto de que cada una de ellas determina a cada ser humano. Schopenhauer dice: "Mientras que todo hombre debe ser tomado por un fenómeno de la voluntad particularmente determinado y caracterizado, al mismo tiempo, de alguna manera, [debe ser tomado,] como idea particular [eigene Idee]" (Schopenhauer, 1986: \$26, 198). Esta afirmación explica la palabra utilizada en la cita de la sección anterior, a saber, el carácter y explica a su vez qué entiende Schopenhauer por la expresión carácter es destino.

Retomando la temática kantiana sobre el carácter inteligible y el carácter empírico, Schopenhauer considera que las ideas constituyen el carácter inteligible de los hombres en tanto que fenómenos con carácter empírico. Por ello los hombres, en tanto que fenómenos, no existen libremente, sino que se encuentran sometidos, no sólo a las determinaciones exteriores de otros fenómenos, sino a su propia idea. Así, para Schopenhauer, como para Agustín o Lutero, la idea de una voluntad libre no exhibe más que un vulgar pelagianismo (Schopenhauer, 1986: \$70, 551).

Además de tener un destino propio, que no es sólo el género, como en el caso de los animales, el hombre también se distingue por poseer intelecto (Schopenhauer, 1986: \$\$26-27, 200), que es, como piensa Schopenhauer, uno de los más altos grados de objetivación de la voluntad (Stanek, 2010: 257). ${ }^{14}$ El intelecto contribuye a conocernos en tanto que fenómenos de la voluntad. Cuando dicha capacidad ha sido llevada a su nivel máximo se origina lo que Schopenhauer denomina "estado moral". El estado moral es el estado de conocimiento perfecto, aunque abstracto y racional, en el que existe una relación necesaria entre todos los fenómenos. Cuando un ser humano se encuentra en el estado moral siente compasión por todos los seres del mundo. Gracias a él tienen origen las virtudes morales que podrían conducir a la negación de la voluntad. ${ }^{15}$

${ }^{14}$ Vincent Stanek toca un punto importante al decir que "c'est la raison qui rend possible une véritable affirmation de soi de la volonté de vivre (comme elle condition aussi [...] sa négation)” (2010: 257). Pero la importancia de la razón en Schopenhauer reside en que gracias a ella nos individualizamos aún más. La razón no contribuye a la negación de la negación determinada. Al contrario, reafirma nuestro carácter fenoménico.

${ }^{15}$ En el suplemento al parágrafo $\$ 68$ del libro cuarto, Schopenhauer distingue entre un pasaje momentáneo, como el acto moral, o la creación artística y la permanente negación (Schopenhauer, 1977: $\$ 48,713)$. 
La desilusión es el rasgo característico de este estado moral virtuoso, pues es señal de que el velo de Maya ha caído. Una vez que el velo ha caído, el hombre virtuoso descubre que la negación determinada es sólo una apariencia y que la vida sólo es sueño. ${ }^{16}$ El estado de desilusión puede dar origen a notables fenómenos morales, como a la persona justa o la filosófica. El estado de desilusión es, como Schopenhauer lo expresa, uno de los últimos pasos antes de cumplir con la verdadera negación, pero no es claro si éste es un paso necesario antes de la verdadera negación de la voluntad. Lo que es claro es que dichos estados morales no constituyen la verdadera negación de la negación o negación de la voluntad en el individuo, sino que son una especie de punto límite respecto del cual la razón no puede ir más lejos.

Todo hombre podría arribar a este estado moral privilegiado pues dicho estado es el resultado de un descubrimiento de la razón, y la razón es característica de todo ser humano. La razón contribuye a este estado moral en la medida en que permite un conocimiento abstracto del carácter sufriente pero también aparente del mundo. Pero dado que querer negar la voluntad del fenómeno por medio de aquello que lo reafirma con más potencia, a saber, la razón, sería contradictorio, Schopenhauer no puede admitir que la vía racional sea la que nos conduce a la verdadera negación. Ciertamente, dice Schopenhauer, la tarea última de la inteligencia es la abolición del querer al que había servido, pero esta inteligencia, continúa diciendo, no es sino un paso transitorio hacia una región a la que el conocimiento no podrá jamás acceder. ${ }^{17}$

Pero entonces ¿̨cómo puede negarse la voluntad en la negación determinada, que es el fenómeno, si ahora es claro que el tránsito hacia el mundo como voluntad o el acceso a la "cosa en sî" no puede estar mediado ni por la voluntad ni por la razón? Para entender cómo es esto posible es necesario movilizar el concepto de gracia.

${ }^{16}$ La negación determinada se ha revelado como una apariencia. Esta apariencia de la primera negación es lo que Schopenhauer asocia al conocimiento de Calderón de la Barca o a estos versos de Shakespeare: "We are such stuff / As dreams are made of, and our little life / Is rounded with sleep" (Tempest. Act. 4. Escena I; citado en Schopenhauer, 1986: \$5, 49). La transformación del fenomeno en mera apariencia es una diferencia importante entre Schopenhauer y el propio Kant, para quien Erscheinungy Schein son términos diferenciados. En cambio, para Schopenhauer el término de apariencia constituye la verdad del fenómeno. El fenómeno es, por tanto, no sólo aquello en lo que podemos basar nuestro conocimiento objetivo, sino también un sueño.

${ }^{17}$ Schopenhauer dice: "Die moralischen Tugenden sind eben nicht der letzte Zweck, sondern nur eine Stufe zu demselben. Diese Stufe ist im Christlichen Mythos bezeichnet durch das Essen vom Baum der Erkenntniß des Guten und Bösen, mit welchem die moralische Verantwortlichkeit zugleich mit der Erbsünde eintritt. Diese selbst ist in Wahrheit die Bejahung des Willens zum Leben; die Verneinung desselben hingegen, in Folge aufgegangener besserer Erkenntniß, ist die Erlösung. Zwischen diesen Beiden also liegt das Moralische [...]” (Schopenhauer, 1977: \$48, 711). 


\section{Gracia}

La negación de la negación determinada, es un tipo específico de negación que hace posible el acceso a la 'cosa o en sí', o a la voluntad. Dicha negación particular habrá de conducirnos hacia la positividad de la voluntad. Ese acceso tiene que poder ser posible a través de la negación de la voluntad en el fenómeno, es decir, tiene que operarse desde dentro del fenómeno, pues ningún poder externo puede destruirla (Schopenhauer, 1986: $\$ 59,446) .{ }^{18}$

Pero la negación que importa en la filosofía de Schopenhauer no puede ser la negación simple de la negación determinada, es decir, no puede ser la mera supresión o aniquilación del fenómeno, prisionero de una serie causal necesaria, mediante la voluntad (suicidio); ni se trata de negarla mediante el conocimiento (estado moral), el cual conduce a la compasión. La negación de la voluntad no puede ser la consecuencia de un acto $^{19}$ ni consecuencia de un querer (pues querer es ejercer la voluntad, no negarla), ni consecuencia de un conocimiento (pues el conocimiento opera con la oposición entre un sujeto y un objeto). Por eso Schopenhauer afirma que la negación de la voluntad es "un estado que, sin embargo, no se puede llamar propiamente conocimiento, puesto que no tiene ya la forma de sujeto y objeto, además de ser accesible únicamente a la experiencia propia e incomunicable" (Schopenhauer, 1986: \$71, 557; Schopenhauer, 2009: \$71, 473).

Schopenhauer organiza una intrépida respuesta a la pregunta por aquello que hace posible el acceso a la "cosa en sí". Como acabamos de ver, su respuesta rechaza la voluntad individual o el conocimiento como vías de acceso, privilegiando, más bien, a la experiencia. Pero no se trata de cualquier tipo de experiencia, sino de aquella definida por la irrupción de la libertad, ${ }^{20}$ que es, como Schopenhauer afirma citando a Malebranche, un misterio (Schopenhauer, 1986: \$70, 548).

\footnotetext{
${ }^{18}$ Nada exterior a la voluntad puede negarla pues no hay nada exterior a la voluntad. Lo enteramente positivo carece de otredad. Ella no es positiva por tener una contraparte negativa, que sería la apariencia, sino que es pura positividad en la medida en que es. La negación de lo que es, se da desde el no ser. Pero al negarse el no ser se niega la negatividad del ser, con lo cual emerge la pura positividad de la "cosa en sî" o Voluntad.

${ }^{19}$ Ningún tipo de acto puede representar la salvación pues se inscriben en un orden causal, incluso los actos piadosos. Para Schopenhauer no hay equilibrio posible en la justicia humana pues dado que los actos están relacionados, un acto justo aquí se convierte inmediatamente en un acto injusto allá.

${ }^{20}$ Líneas arriba observamos que Schopenhauer caracterizó a la libertad como lo "negativo", pero ese epíteto servía para subrayar su carácter de in-determinación. La libertad es un concepto negativo solo en comparación con la determinación fenoménica, pero es pura positividad en la medida en que carece absolutamente de negación determinada.
} 
El misterio reside en que un elemento que se define por la ausencia de determinaciones o de causas, incide en el mundo de las causas y determinaciones, a saber, en el mundo de la necesidad. Este misterio es la Gracia ${ }^{21}$ a la que Schopenhauer caracteriza, precisamente, como el reino de la libertad. La necesidad es el reino de la naturaleza; la libertad es el reino de la gracia. La negación del querer, aquella entrada en la libertad, no puede conseguirse a la fuerza a base de propósitos, por lo que llega de repente y como caída del cielo (Schopenhauer, 1986: \$70, 549; Schopenhauer, 2009: \$70, 467).

La gracia es un evento gratuito que no se encuentra relacionado, de ninguna manera, con lo que es resultado de la necesidad del mundo considerado en tanto que representación: ni con el conocer, ni con el hacer. Así, el acceso a la "cosa en sî" o a la positividad de la voluntad (como lo opuesto a la representación, que es negación determinada), sólo es posible mediante la irrupción contingente e inopinada del misterio de la gracia. Ahora bien, la gracia, como manifestación de la libertad en el mundo de la más férrea necesidad, se vive como ascesis.

Como se adelantaba líneas arriba, el mero conocimiento de la relación entre todos los fenómenos, y la clara conciencia de la injusticia y el sufrimiento del mundo no es un motivo, es decir, una causa en el ámbito moral, que ocasionaría la negación de la voluntad. ¿Por qué? Porque este conocimiento es abstracto, no es vivencia de la unidad sufriente del todo (Schopenhauer, 1986: $\$ 68,520$; Schopenhauer, 2009: $\$ 68,444)$. Sólo la experiencia o la vivencia del sufrimiento y la renuncia a la voluntad individual permiten el acceso a aquel nihil negativum que es la "cosa en sî". Por ello Schopenhauer cita al Maestro Eckhart para quien "el animal más rápido que puede conducirte a la perfección es el sufrimiento” (Schopenhauer, 1977: $\$ 48,743)$.

A diferencia del hombre justo, quien contempla el sufrimiento en el mundo como si fuese una consecuencia lógica que se desprende del hecho de que todos los fenómenos están relacionados causalmente, el asceta no se conforma con saber, sino que, a través de la mortificación, padece el sufrimiento que los moralistas o filósofos conocen sólo a través de un razonamiento. A diferencia del genio artístico o del genio moral, el asceta no perpetúa el círculo infinito del deseo, sino que vive negando la voluntad en él mismo. Este actuar negador debe, no obstante, caracterizarse como un no-acto, o un anti-acto.

\footnotetext{
${ }^{21}$ Schopenhauer dice: "einer Erfahrung, die zwar nicht Jedem zugänglich ist, sondern nur wenigen Begünstigten zu Theil wird, daher sie den Namen Gnadenwirkung erhalten hat, an deren Wirklichkeit jedoch aus obigen Gründen nicht zu zweifeln ist” (Schopenhauer, 1977: \$47, 718).
} 
La negación de la voluntad no es un acto moral, sino que se encuentra fuera del radio de toda acción. Todo acto no hace sino prolongar la cadena causal del mundo fenoménico “operari sequitur esse” (Schopenhauer, 1977: \$48, 690). Por tanto, negar la voluntad en el fenómeno es el anti-acto que dentro del mundo fenoménico abre una especie de territorio neutral. Eso es la manifestación de lo sagrado. $^{22}$

Con la introducción de la Gracia y de la negación de la voluntad fenoménica mediante la ascesis, Schopenhauer se desmarca de las soluciones racionalizantes al problema del acceso a la "cosa en sî". Además de privilegiar una experiencia mística para hablar de la disipación de las fronteras entre fenómeno y voluntad, Schopenhauer introduce otro elemento, inexistente en el idealismo canónico, a saber, el de contingencia. El concepto de gracia implica la más absoluta contingencia, lo cual se contrapone al necesitarismo de la razón.

Contrariamente a Fichte o Hegel, Schopenhauer considera, que, para alcanzar aquel aspecto totalmente positivo del ser, no basta con conocer, sino que es necesario sufrir. Para hacer del sufrimiento un anti-acto es necesaria la intervención totalmente libre, misteriosa y gratuita, de la gracia, mediante la cual se rompe la necesidad y la cadena causal en la que están implicados los actos. El sufrimiento aceptado es el camino que asegura el cese de la voluntad de vivir. Así, la negación de la voluntad puede caracterizarse como el cese del movimiento de la voluntad individualizada, cuyo origen es, más que un conocimiento racional, una inopinada experiencia de la nihilidad. Al respecto Schopenhauer afirma que "después de que nuestra investigación nos ha llevado a reconocer en la santidad perfecta la negación y supresión de todo querer, y con ello la salvación de un mundo cuya existencia se nos presentaba en su totalidad como sufrimiento, todo eso se nos aparece como un tránsito al vacío de la nada” (Schopenhauer, 1986: \$71, 554-555; Schopenhauer, 2009: \$71, 474).

Esta nada, resultado de la negación de la negación determinada es la absoluta positividad de la voluntad como "cosa en sî", es decir, idéntica a la esencia misma de las cosas a la que Schopenhauer se refería cuando hacía alusión a la distinción metafísica entre esencia y existencia. Pero esta experiencia de la nihilidad, precisa Schopenhauer, se percibe como tal desde el mundo dominado por las determina-

\footnotetext{
${ }^{22}$ Schopenhauer precede a Rudolf Otto en la observación de que lo sagrado no se inscribe en el marco de la moral. Otto agrega que la "voluntad santa", como es llamada por Kant, es un error de apelación (Otto, 2015: 26).
} 
ciones fenoménicas. ${ }^{23}$ Por ello, en tanto que fenómenos, no podemos hablar de un nibil negativum como un concepto positivo.

Esta precisión es, al mismo tiempo, una precaución que se relaciona de manera inmediata con la así llamada humildad epistémica kantiana. Es esta humildad epistémica la que le impide a Schopenhauer atribuirle a la razón la llave de acceso al mundo de la Voluntad, y constituye otra diferencia fundamental entre Schopenhauer y los demás idealistas pues Schopenhauer reconoce que ni siquiera la filosofía puede atreverse a afirmar a ciencia cierta qué sea o qué pueda resultar de la negación de la negación determinada ya que la/el filósofo no posee la experiencia directa de esta nihilidad (Schopenhauer, 1996: \$71, 557).

Así, se abre otro ámbito de saber, un saber positivo que podría, por otra parte, encontrarse relacionado con la propuesta schellinguiana de una filosofía positiva. Este tema amerita, no obstante, otro espacio para ser desarrollado.

${ }^{23}$ Esta apelación de la nada como "nada” es una apelación por defecto. Más arriba se señaló el parentesco entre Schopenhauer con la postura neoplatónica. Ahora también habrá de notarse la relación entre los neoplatónicos y el Maestro Eckhart, a quien, como se percibe a lo largo de El Mundo, Schopenhauer conoce y aprecia. Juntunen dice: "Eckhart befindet sich damit auf gleicher Linie wie die Neoplatoniker und Pseudo-Dionysios: Gott ist so viel höher als die Kreaturen, dass alle Fähigkeiten der menschlichen Sprache nicht ausreichen, über ihn zu sprechen. Die menschliche Sprache kann allein von den Seienden sprechen, Gott aber ist kein Seiendes, sondern die Ursache der Seienden. Deshalb kann er nicht mit positiven Begriffen beschrieben werden. Gott ist für Eckhart 'Ein nitgot, Ein nit-geist, Ein nit-persone' und auch einfach 'niht'” (Juntunen, 1996: 111). 


\section{Bibliografía}

Aristóteles. (1995). Tratados de Lógica (Órganon) II: Sobre la Interpretación. Analiticos primeros. Analiticos segundos (Miguel Candel San Martín, Trad.). Madrid: Gredos.

Boss, Marc. (2010). "Chorismos, Methexis et coïncidence des opposés. Ernst Cassirer Interprète du platonisme de Nicolas de Cues". Études théologiques et religieuses, (3), 371-386.

DAstur, Françoise. (2018). Figures du néant et de la négation entre orient et occident. Paris: Les belles lettres.

Fichte, Johann Gottlieb. (1965). Grundlage der gesamten Wissenschaftslehre. Werke 1793-1794 (Reinhard Lauch y Hans Jacob, Eds.). Stuttgart-Bad Cannstatt: Bayerischen Akademie der Wissenschaften; Friedrich Frommann.

HüHN, Lore. (2005). “Die Wiederkehr des Verdrängten. Überlegungen zur Rolle des Anfangs bei Schelling und Schopenhauer”. Schopenhauer Jahrbuch, (86), 55-69. Juntunten, Sammeli. (1996). Der Begriff des Nichts bei Luther in den Jahren von 1510 bis 1523 . Helsinki: Luther-Agricola-Gesellschaft.

Kant, Immanuel. (2008). Crítica de la razón pura (Mario Caimi, Trad.). México: FCE; UNAM; UAM.

OchоA, Hugo. (2003). "Razón y fe, un diálogo entre Kant y Jacobi”. Teología y Vida, 4(44), 410-422. doi: http://dx.doi.org/10.4067/S0049-34492003000400004

Отто, Rudolf. (2015). Le sacré (André Jundt, Trad.). Paris: Payot.

SAFranski, Rüdiger. (1991). Schopenhauer y los años salvajes de la filosofía (José Planells Puchades, Trad.). Madrid: Alianza.

Schelling, Friedrich Wilhelm Joseph von. (1907). Vom Ich als Prinzip der Philosophie Werke. Vol I. Leipzig.

Schopenhauer, Arthur. (1977). Die Welt als Wille und Vorstellung. Ergänzungen zum vierten Buch. Zürcher Ausgabe. Werke in zehn Bänden, IV. Zürich: Diogenes Verlag.

Schopenhauer, Arthur. (1981). La cuádruple raíz del principio de razón suficiente (L. E. Palacios, Trad.). Madrid: Gredos.

Schopenhauer, Arthur. (1986). Die Welt als Wille und Vorstellung I. Frankfurt am Main: Suhrkamp.

Schopenhauer, Arthur. (2009). El mundo como Voluntad y representación (Pilar López de Santa María, Trad.). Madrid: Trotta.

StaneK, Vincent. (2010). La métaphysique de Schopenhauer. Paris: Vrin. 